\title{
BOLSTERING RESILIENCE: BENEFITING FROM LESSONS LEARNED
}

\author{
Donald Meichenbaum, Ph.D. \\ Distinguished Professor Emeritus, \\ University of Waterloo \\ Waterloo, Ontario, Canada \\ and \\ Research Director of \\ The Melissa Institute for Violence Prevention and \\ Treatment of Victims of Violence \\ Miami, Florida \\ (www.melissainstitute.org)
}

This Chapter will appear in Brom, D., Pat-Horenczyk, R. \& Ford, J. (Eds.). (2008).

Treating traumatized children: Risk, Resilience and Recovery. New York:

Routledge. 


\section{PROLOGUE}

After 30 years as a Professor of Clinical Psychology at the University of Waterloo, in Ontario, Canada, I took early retirement to become Research Director of the Melissa Institute, in Miami, Florida (www.melissainstitute.org). In this capacity, I have been involved in consultation and training with clinicians and researchers who deal with "victimized" children, youth and their families. The following list provides a sampling of the diverse groups that I have been called upon to work with in the past 10 years. As you read this list, please put yourself in my shoes and consider how you would help nurture "resilience" in each of these diverse traumatized populations. What guidelines do you think the research literature provides that would influence your consultative advice? The samples include:

1. Children and youth who were directly exposed to violence at Oklahoma City, Columbine school shooting, and the September, 11 events in New York;

2. Youth who have been incarcerated in the Juvenile Justice system, some $70 \%$ of whom have a history of having been victimized, and they now meet diagnostic criteria for PTSD and related psychiatric disorders;

3. Minority children raised in high poverty crime-infested areas in Los Angeles, New Orleans after Hurricane Katrina, and in Miami. For example, an 8 year-old- 
who was playing dolls with her girlfriend. They were playing "bury the dolls." During the game she was murdered in a drive-by gang shootout.

4. Children who have been sexually or physically abused, and in about $40 \%$ of the cases, they have also witnessed domestic violence in their homes.

5. Children who have been repeatedly victimized at school as a result of bullying;

6. Native populations, both in the United States and in Canada, where there has been repeated and massive victimization. For example, among the Inuit youth in Canada, a male reading instructor sexually abused 86 youth in three communities over a period of six years (see Meichenbaum, 2005).

7. Children and youth who are in Residential Treatment Centers with a history of victimization. For example, consider a recent case of a ten year old girl who was repeatedly sexually abused by her step-father and she was threatened that if she told anyone, something "terrible" would happen. To get his point across, the stepfather beheaded her pet dog in front of her and told her that if she told anyone this would happen to her younger brother.

8. Finally, children with no history of victimization, but who live in high-risk areas for natural disasters and exposure to violence. 
9. To this list one can add the innumerable children who are being victimized. (See the U.N. Study on Violence Against Children -- www.violencestudy.org)

The challenge is how to provide both preventative and treatment interventions designed to bolster resilience and build on existing and potential strengths in such diverse victimized and high-risk groups of children, youth, families and communities. What can be done at the primary prevention level which focuses on the universal implementation of intervention for all children? (For example, children who are living in high-risk poverty environments and high-risk environments due to exposure to repetitive natural disasters or exposure to ongoing violence). What can be done at the secondary prevention level that targets children and youth already at risk? (For example, children who are repeatedly bullied or who are the offspring of dysfunctional and psychiatrically disturbed parents). What can be done at the tertiary level which provides interventions with selected populations of children and youth who evidence persistent needs and challenging behaviors and who require comprehensive wrap-around services? (For example, incarcerated youth who have a history of neglect and victimization or children and Native youth who evidence the psychiatric sequelae of sexual and physical abuse)

The answers to these challenging questions should be informed by what the research literature tells us about the developmental nature of resilience. What are the lessons to be learned that should guide interventions? 


\section{LESSONS TO BE LEARNED ABOUT RESILIENCE}

1. It is estimated that $25 \%$ of American youth experience serious traumatic events by their $16^{\text {th }}$ birthday. Children and youth frequently experience different types of victimization on multiple occasions, rather than being exposed to unique singular experiences. There is an overlap of different types of victimization experiences such as living in high-risk crime-saturated poverty areas, witnessing violence at home, and experiencing neglect and abuse. Most instances of exposure to violence occurs within a youth's immediate environment (home, school, neighborhood) and is most often perpetrated by a family member or acquaintance (Garbarino et al., 1992).

Lesson: There is a need to reduce and remove exposure to multiple risk factors and a need to address the cumulative complex impact of multiple victimization experiences.

2. Research indicates it is the total number of risk factors present that is more important than the specificity of risk factors that impact developmental outcomes. Risk factors often co-occur and pile up over time. For example, Sameroff and his colleagues (1992) studied the influence of social and family risk factors on the stability of intelligence from preschool to adolescence. They found that the pattern of risk was less important than the total amount of risk present in the 
child's life.

Lesson: There is a need to systematically assess for the cumulative exposure to adverse childhood experiences (Edwards et al., 2005). Moreover, interventions to nurture resilience need to target multiple systems.

3. Exposure to chromic traumatic stressors in the developing years can cause changes that impact memory and cognition. More specifically, violence exposure can reduce the youth's ability to focus attention, organize and process information and contribute to decreased IQ and reading ability, lower academic performance, increase days of school absence and decrease rates of high school graduation. The rates of suspensions and expulsions from school are also associated with the students' exposure to community violence (Wong et al., 2007). Moreover, lowincome and ethnic minority youth disproportionately experience higher rates of violence with the consequent academic sequelae for which they usually do not receive interventions (Delaney-Black et al., 2002; Grogger, 1997: Hurt et al., 2001).

As Kataoka et al. (2006) observe:

"Violence exposure before $6^{\text {th }}$ grade is associated with higher rates of school suspensions and expulsions and lower rates of attendance. Results of a survey of $28006^{\text {th }}$ grade students suggest 
that the traumatic effects of violence appear to account for $50 \%$ of the learning gap experience by students.” (pp 151-152).

Lesson: There is a need to address explicitly the academic needs of victimized children and work on enhancing their "school connectedness" or feeling of membership in the school that they attend by the use of mentoring programs (Dubois \& Karcher, 2005). For instance, one can ask at-risk youth the following questions in order to assess the degree to which they feel they can "connect" with a supportive adult at their school.

"If you were absent from school, who besides your friends would notice you were missing and would miss you?" (Identify a supportive adult by name.)

"If you had a problem or major concern, who at your school could you go to for help?"

"Is there a teacher or staff member to whom you would turn to, if you needed help with a personal problem?"

4. Exposure to recurrent or prolonged trauma, especially if the onset occurs during early childhood can cause neurobiological changes such as: 
(i) the reduction in the volume and activity levels of major brain structures such as the corpus callosum and the limbic system;

(ii) impairment of the left hemisphere functioning and negatively affect the Hypothalamic-Pituitary Axis - HPA;

(iii) increased hypersensitivity to cortisol levels;

(iv) increased sympathetic nervous system activity.

Such bodily changes can result in exaggerated startle responses, PTSD, a compromised immune system, increased vulnerability to depression and a failure to develop self-regulatory functions, especially in the development of language, attentional and memory capabilities (Curtis \& Cicchetti, 2003; DeBellis et al., 1999; DeBellis, 2002; Fletcher, 1996; Streech-Fisher \& van der Kolk, 2000).

Lesson: There is a need to provide such children with skills training to compensate for self-regulatory deficits and provide them with "metacognitive prosthetic devices" to compensate for the neurobiological deficits that follow from chronic traumatic experiences. These metacognitive supports may include the use of advance organizers, memory prompts, self-instructional training and other forms of cognitive-behavioral interventions that are described on www.teachsafeschools.org. In addition, there is a need to reduce high-risk behaviors that can lead to revictimization (e.g., substance abuse and aggressive behaviors, sensation-seeking behaviors, sexual acting out-behaviors) (Alvord \& Grados, 2005; Grotberg, 2003). 
5. Trauma exposure can have a negative impact on the development of attachment behaviors. For example, victimized abused teenage girls are more likely to hold in their feelings and have extreme emotional reactions. They have fewer adaptive coping strategies and have problems handling strong emotions, particularly anger. They have limited expectations that others can be of help. They show deficits in the ability to self-soothe and modulate negative emotions (Berman et al., 1996; Haggerty et al., 1996 Kendler et al., 2000).

Lesson: Helpers need to make special efforts to develop and monitor a collaborative therapeutic alliance with traumatized youth and address therapyinterfering behaviors (Bertolino, 2003; Miller et al., 2007).

As Masten and Reed (2002) observe:

The best documented asset of resilience is a strong bond to a competent caring adult, which need not be a parent. For children who do not have such an adult involved in their lives, it is the first order of business. Children also need opportunities to experience success at all ages.

6. Not all children and youth who are exposed to traumatic events develop behavioral and mental health problems. In fact, resilience appears to be the general rule of adaptation. This conclusion holds whether the children who are studied have experienced premature birth, physical illness and surgery, 
maltreatment (abuse/ neglect), poverty exposure to marital discord and domestic violence, to trauma of war and natural disasters, or are the offspring of mentally ill, alcoholic, or criminally-involved parents. (DeAngelis, 2007; Masten, 2001; 2004; Masten \& Gewirtz, 2006). As Bernard (1995) observes, 1/2 to 2/3 of children living in such extreme circumstances grow up and "overcome the odds," and go on to achieve successful and adjusted lives.

Lesson: There is a need to incorporate into interventions designed to bolster resilience the attributes and the circumstance that contribute to the capabilities to cope effectively in the face of adversities and difficulties. The Search Institute (www.Search-Institute.org) has enumerated some forty developmental assets that are the building blocks of positive youth development. Interventions should nurture these assets that include:

a) commitment to learning and a motivation to do well in school and the accompanying activities of feeling connected to school, participating in school activities, completing homework, reading for pleasure;

b) positive values and a prosocial attitude of being empathic, understanding, honest, and responsible, and practicing self-restraint in relation to substances and sexual activity;

c) social competence as reflected in the ability to resolve conflicts peacefully, resist negative peer pressure and make friends; 
d) positive identity which includes assets such as having high self-esteem, a sense of purpose in life, and plans for the future.

Resilience is not a trait that a youth is born with or automatically keeps once it is achieved. Resilience is a complex interactive process that entails characteristics of the child, the family, extrafamilial relationships and school/community factors.

7. When considering the features of so-called resilient children, it is important to keep in mind that children may be resilient in one domain of their lives, but not in other areas (e.g., academic, social, self-regulating behaviors). As Zimmerman and Arunkumar (1994) observe:

Resilience is not a universal construct that applies to all life domains. Children may be resilient to specific risk factors, but quite vulnerable to others. Resilience is a multidimensional phenomenon that is context specific and involves developmental changes. (p. 4)

Resilience should be viewed as being "fluid over time." The relative importance of risk and protective factors change at various phases of life. A child who may be resilient at one developmental phase may not be necessarily resilient at the next developmental phase. Developmental transition points at school and at puberty are particularly sensitive times for the impact of traumas. Protective efforts at bolstering resilience should be sensitive to these developmentally vulnerable periods. 
8. Protective factors differ across gender, race and cultures. For instance, girls tend to bolster their resilience by building strong caring relationships, while boys are more likely to build resilience by learning how to use active problem-solving (Bernard, 1995). Further evidence that resilience may yield gender differences comes from the longitudinal research by Werner and Smith (1992) who found that scholastic competence at age 10 was more strongly associated with successful transition to adult responsibilities for men than for women. On the other hand, factors such as high self-esteem, self-efficacy and a sense of personal control were more predictive of successful adaptation among the women than men. In the stress domain, males were more vulnerable to separation and loss of caregivers in the first decade of life, while girls were more vulnerable to family discord and loss in the second decade of life.

Lesson: The factors that influence resilience differ for males and females and interventions need to be gender-sensitive. (For examples of such programs see www.melissainstitute.org). Another source of variability to be considered in resilience-based interventions is the cultural background. For instance, Kataoka and her colleagues (2006) provide a description of how a culturally-sensitive faith-based community intervention can be used to bolster resilience of children who have been exposed to neighborhood violence. They combined an evidencebased intervention (Cognitive-Behavioral Intervention for Trauma in Schools CBITS) with spirituality, as reflected in the use of religious coping strategies of 
prayer, religious relaxation imagery and local faith-based healers. As one mother commented,

“My boy was afraid from the day he was terrorized. He wouldn't go outside. I remember at night he would pray and ask Jesus to give him comfort." (Kataoka et al., 2006)

It is important to note, however, that faith and spirituality, operate as a stronger protective factor in some cultures than in others.

9. There are multiple pathways to resilience. Resilient children and youth possess multiple skills in varying degrees that help them cope with adversities. These response skills can be strengthened, as well as learned. Among other skills resilient individuals make wise choices and they take advantage of opportunities (e.g., continuing their education, learning new skills, joining the military, choosing healthy life partners, and breaking away from deviant peers.) (Werner \& Smith, 2001).

Lesson: It is important for mental health care providers to build upon the specific positive behaviors and coping techniques that individuals already use to deal with suffering and disability and capitalize on and nurture their innate self-healing capacities. Health care providers can aid survivors in enhancing their coping skills by pointing out techniques already in place that they have utilized in the recovery process. 
In order to help survivors, health care providers can encourage and recommend altruistic behaviors, independent activities, and the use of spirituality. By helping others, survivors in effect, are helping themselves. By encouraging independent activities such as school work or work in general, this enhances the recovery process. By means of using spirituality, survivors can reclaim values and foster meaning and hope (Kataoka et al., 2006; Mollica, 2006).

For example, at a recent clinical consultation a youth who had a remarkable history of victimization was encouraged and challenged to use his talent and interest in poetry as a form of healing and as a way to transform his life. There is a need to help victimized youth use their "islands of competence" to foster a sense of accomplishment.

10. Most victimized children and youth do not receive services and very few are treated with evidence-based interventions. For example, only $25 \%$ of children with emotional and behavioral problems in the U.S. receive specific mental health services.

The hopeful news is that there are now several evidence-based interventions that have been employed successfully with traumatized children. Schools are the best settings to identify at-risk children and to provide mental health interventions (Alvard \& Grados, 2005; Battistich et al., 1996; Cohen et al., 2006; Cowen, 2000; Doll \& Lyon, 1998; Eber et al., 1996; Ennett et al., 2000; Huang et al., 2005; 
Jennings et al., 2000; Rutter et al., 1979; Tobler \& Stratton, 1997; Stein et al., 2003; Weisz et al., 2005; Wong et al., 2007).

In conclusion, the research literature on resilience in children has yielded important lessons or guidelines to follow when implementing preventative and treatment interventions. But it will take more than research to bolster the resilience of victimized children. It will take political leadership and public commitment to bolster children's resilience. Consider the words of a youth in New Orleans, as reported in a pictorial essay of the Children of the Storm by Jason DeParle (N.Y. Times, August 27, 2006). The youth was asked if there was anything else he wants people to hear:

“My house was flooded and burglarized, my father, a National

Guardsman, is in the Middle East and someone killed my dog. We deserve better!" 


\section{REFERENCES}

Alvord, M.K., \& Grados, J.J. (2005). Enhancing resilience in children: A proactive approach. Professional Psychology: Research and Practice, $\underline{36}$, 238-245.

Battistich, V., Scheps, E., Watson, W., \& Solomon, D. (1996). Preventative effects for the Child Development Project. Journal of Applied Developmental Psychology; $11,12-35$.

Berman, S. L., Kurtines, W. M., Silverman, W. K., \& Serafini, L. T. (1996). The impact of exposure to crime and violence on urban youth. American Journal of Orthopsychiatry, $\underline{66}, 329-336$.

Bernard, B. (1995). Fostering resiliency in kids: Protective factors in the family, school and community. San Francisco: Far West Laboratory for Educational Research and Development.

Bertolino, B. (2003). Change-oriented therapy with adolescents and young adults. New York: Norton.

Cohen, J. A., Mannarino, A. P., \& Deblinger, E. (2006). Treating trauma and traumatic grief in children and adolescents. New York: Guilford Press.

Cowan, E. (2000). Psychological wellness: Some hopes for the future. In D. Cicchetti, J. Rappaport, I. Sandler \& R. P. Weissberg (Eds.), The promotion of wellness in adolescents. (pp. 477-503). Washington, DC: Child Welfare League of America Press.

Curtis, W. J. , \& Cicchetti, D. ( 2003) . Moving research on resilience into the 21st century: Theoretical and methodological consideration in examining biological contributions to resilience. Development and Psychopathology, 15, 773-810. 
De Angelis, T. (2007). A new diagnosis for childhood trauma? Monitor on Psychology, $\underline{38}, 32-34$.

DeBellis, M. D. (2002). Developmental traumatology. Psychoneuroendocrinology, 27, 155-170.

DeBellis, M.D., Baum, A., Birmaher, B., et al. (1999). Developmental traumatology. Part 1: Biological stress systems. Biological Psychiatry, 45, 1259-1270.

Delaney-Black,V.\& Covington, C. Ondersma, S. J. et al. (2002) Violence exposure, trauma, and IQ and/or reading deficits among urban children. Archives of $\underline{\text { Pediatrics and Adolescent }}$ Medicine, 156, 280-285.

Doll, B., \& Lyon, M. A. (1998). Risk and resilience: Implications for delivery of educational and mental health services in schools. School Psychology Review, 27, 348-363.

Dubois, D. L., \& Karcher, M. J. (Eds.). (2005). Handbook of youth mentoring. Thousand Oaks, CA: Sage Publications.

Eber, L., Osuch, R., \& Reddott, C. (1996). School-based application of the wraparound process: Early results in service provision and student outcomes. Journal of Child and Family Studies, $\underline{5}, 83-99$.

Edwards, V. J., Anda, R. F., Dube, S. R., Dong, M., Chapman, D. P., \& Felitti, V. J. (2005). The wide-ranging health outcomes of Adverse Childhood Experiences. In K. A. Kendall-Tackett \& S. M. Giaromoni (Eds.), Child victimization. (pp. 8-12). Kingston, NJ: Civic Research Institute. 
Ennett, C. T., Ringwalt, C. L. et al. (2003). A comparison of current practice in schoolbased substance use prevention programs with meta-analysis findings. Prevention Science, $\underline{4}, 1-14$.

Fletcher, K.E. (1996). Childhood posttraumatic stress disorder. In E. Mash \& R. Barkley (Eds.). Child Psychopathology (pp. 242-276). New York: Guilford Press.

Garbarino, J., Debra, N., Kostelny, K, \& Pardo, . (1992). Child in charge: Coping with the consequences of community violence. San Francisco, CA: Jossey-Bass

Grogger, J. (1997) . Local violence and educational attainment. Journal of Human Resources, $\underline{32}$, 659-682.

Grotberg, E.H. (Ed.) (2003). Resilience for today: Gaining strength from adversity. Westport, CT: London Praeger.

Haggerty, J., Sherrod, L., Garmezy, N., \& Rutter, M. (1996). Stress, risk and resilience in children and adolescents. New York: Cambridge University Press.

Huang, J., Strand, B., Friedman, R., et al. (2005). Transforming mental health care for children and their families. American Psychologist, $\underline{60}, 615-627$.

Hurt, H. Malmud, E.,Brodsky, N. L. \& Giannetta, J. (2001). Exposure to violence: Psychological and academic correlates in child witnesses. Archives of Pediatrics and Adolescent Medicine, 155, 351-356.

Jennings, J., Pearson, G., \& Harris, M. (2000). Implementing and maintaining schoolbased mental health services in a large urban school district. Journal of School Health, $\underline{70}, 201-205$. 
Kataoka, S.H., Fuentes, S.O., Donghue, V.P. et al. (2006). A community participatory research partnership: The development of a faith-based intervention for children exposed to violence. Ethnicity and Disease, 16, 89-97.

Kendler, K. S., Bulik, C. M., et al. (2000). Childhood sexual abuse and adult psychiatric and substance abuse disorders in women: An epidemiological and co-twin control analysis. Archives of General Psychiatry, 57, 953-959.

Masten, A. S. (2001). Ordinary magic: Resilience processes in development. American Psychologist, 56, 227-238.

Masten, A. S. (2004). Regulatory processes, risk and resilience in adolescent development. Annals of the New York Academy of Sciences, 1021, 310-319. (Available online at www.annalsnyas.org).

Masten, A. S. \& Gewirtz, A.H. (2006). Resilience in development: The importance of early childhood. In R.E. Tremblay, R.E. Barr \& D. V. Peters (Eds), Encyclopedia on Early Childhood Development, pp. 1-6. Available at http://www.excellenceEarlychildhood.ca/documents/Masten-GewirtzAngxp.pdf

Masten, A. S., \& Reed, M. G. (2002). Resilience in development. In S. R. Snyder \& S. J. Lopez (Eds.), The handbook of positive psychology. Oxford, England: Oxford University Press.

Meichenbaum, D. (2005). 35 years of working with suicidal patients: Lessons learned. Canadian Psychology, $\underline{46}, 64-72$.

Miller, A.L., Rathus, J.H., \& Linehan, M.M. (2007). Dialetical behavior therapy with suicidal adolescents. New York: Guilford Press. 
Mollica, R. F. (2006). Healing invisible wounds: Paths to hope and recovery in a violent world. New York: Harcourt Press.

Rutter, M. B., Maughan, P., Mortimore, J., Ouston, J., \& Smith, A. (1979). Fifteen thousand hours. Cambridge, MA: Harvard University Press.

Sameroff, A. J., Seifer, R. Baldwin, A., \& Baldwin, C. (1992). Stability of intelligence from preschool to adolescence: The influence of social and family risk factors. Child Development, 64, 80-97.

Stein, B.D., Jaycox, L.H., Kataoka, S.H., et al. (2003). A mental health intervention for schoolchildren exposed to violence. Journal of the American Medical Association, 290, 603-611.

Streech-Fisher, A. \& van der Kolk, B.A. (2000). Down will come baby, cradle and all: Diagnostic and therapeutic implications of chronic trauma on child development. Australian and New Zealand Journal of Psychiatry, 34, 903-918.

Tobler, N. S., \& Stratton, H. H. (1997). Effectiveness of school-based drug prevention programs: A meta-analysis of the research. Journal of Primary Prevention, $\underline{18}$, 71-128.

Weisz , J. R., Sandler, I. N., Durlak, J. A., \& Anton, B. S. (2005). Promoting and protecting youth mental health through evidence-based prevention and treatment. American Psychologist, 60, 628-648.

Werner, E. E., \& Smith, R. ( 1992). Vulnerable, but invincible: A longitudinal study of resilient children and youth. New York: Adams, Bannistar and Cox.

Werner, E., \& Smith, R. (2001). Journeys from childhood to midlife: Risk, resilience, and recovery. Ithaca, NY: Cornell University Press. 
Wong, M., Rosamural, M. E., Stein, B.D., et al. (2007). School-based intervention for adolescents exposed to violence. The Prevention Researcher, 14, 17-20.

Zimmerman, M. A., \& Arunkumar, R. (1994). Resiliency research: Implications for schools and policy. Social Policy Report of the SRCD, $\underline{8}, 1-17$. 